Wissenschaftliche Entdeckungen 


\section{WISSENSCHAFT Herausgegeben \\ UND \\ vom Institut \\ GESELLSCHAFT \\ für Wissenschaftstheorie \\ und -organisation \\ der \\ Akademie der Wissenschaften \\ der DDR \\ durch \\ Günter Kröber}

Band 6 


\title{
Wissenschaftliche Entdeckungen
}

\author{
Probleme ihrer Aufnahme \\ und Wertung
}

Herausgegeben in deutscher Sprache von Lothar Kannengießer und Günter Kröber

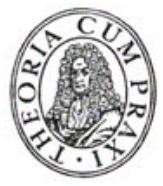

AKADEMIE - VE RLAG - BERLIN

1974 
Russischer Originaltitel:

Научное открытие и его восприятие

изд. Наука, Москва 1971

Ins Deutsche übersetzt von Karl König, Berlin

Erschienen im Akademie-Verlag, 108 Berlin, Leipziger Str. 3-4

Copyright der deutschen Ausgabe 1974 by Akademie-Verlag, Berlin

Lizenznummer: $202 \cdot 100 / 49 / 74$

Gesamtherstellung: IV/2/14 VEB Druckerei "Gottfried Wilhelm Leibniz», 445 Gräfenhainichen $\cdot 4278$

Bestellnummer: 7522391 (2162/6) · LSV 0305

Printed in GDR

EVP 12,- 